\title{
Preimplantation genetic diagnosis and the biopsy technique: Important considerations
}

\author{
Ermanno Greco, Gemma Fabozzi, Alessandra Ruberti, Daniela Zavaglia, Maria Giulia Minasi
}

Centre for Reproductive Medicine, European Hospital, Via Portuense, Rome, Italy; mg.minasi@gmail.com

Received 30 May 2013; revised 15 July 2013; accepted 23 July 2013

Copyright (C) 2013 Ermanno Greco et al. This is an open access article distributed under the Creative Commons Attribution License, which permits unrestricted use, distribution, and reproduction in any medium, provided the original work is properly cited.

\begin{abstract}
Preimplantation genetic diagnosis allows to test the genetic status of embryos prior to implantation. In order to obtain genetic material, on which carry out a genetic diagnosis, a procedure named embryo biopsy is required. In the last two decades, embryo biopsy at the cleavage stage has been the mostly performed procedure. However, recently, alternative methods allowing the retrieval of a larger number of cells (blastocyst stage biopsy), or representing a valid alternative to overcome ethical issues (polar body biopsy) have obtained increasing consensus. This article reviews different methods of embryo biopsy and points out their positive and negative aspects.
\end{abstract}

Keywords: Preimplantation Genetic Diagnosis; Screening; Polar Body; Embryo; Blastocyst Biopsy

\section{INTRODUCTION}

Preimplantation Genetic Diagnosis (PGD) has been conceived as an alternative to fetal prenatal diagnosis. Patients recurring to PGD are couples at risk of transmitting genetically inheritable disorders to their offspring. Most of them are fertile, but have been diagnosed with a specific genetic disease and this technique offers them the possibility to know the health status of their embryos before undertaking the pregnancy [1]. In many cases, they have a previous history of recurrent miscarriages of genetic origin or affected pregnancy terminations following invasive prenatal diagnosis procedure such as amniocentesis or chorionic villus sampling [2]. However, patients are usually advised to further perform prenatal diagnosis to confirm the status of the baby.

PGD diagnoses three main groups of inheritable disease: 1) monogenic disorders, which can affect autosomes or sex chromosomes with autosomal dominant, au- tosomal recessive, X-linked inheritance; 2) triplet repeat disorders, caused by an expansion of a triplet repeat of bases on a chromosome; 3 ) chromosome abnormalities, which can be numerical (aneuploidies) or structural (translocations or inversions) [1,2]. Additionally, PGD can be used to perform sex selection for non-medical reasons, $[3,4]$ to detect mutations that can predispose to specific diseases (such as BRCA1 mutation which predispose to breast cancer) [5], to detect late-onset neurodegenerative disorders such as Huntington's disease [5,6] and for HLA typing [7]. However, the ethical aspects concerning these indications remain controversial and are still under debate $[5,8]$.

PGD technology has been recently used also to examine the genetic status in embryos from infertile couples undergoing IVF. In this case, the methodology is named Preimplantation Genetic Screening (PGS) or PGD for aneuploidy screening [9]. This procedure tests genetic conditions, in the absence of symptoms, with the aim to select "the chromosomally best embryo" for transfer [1]. It does not look for a specific disease; it just screens embryos for the most common genetic pathologies. Patients referred to PGS include couples with a history of repeated implantation failure in IVF, recurrent miscarriages and severe male factor infertility and advanced maternal age (AMA) [1,9,10]. However, different randomized control trials have demonstrated that PGS for AMA patients do not directly improves implantation or pregnancy rates [11-13].

The two main techniques used for genetic diagnosis are fluorescent in situ hybridization (FISH) for cytogenetic analysis of chromosomal abnormalities $[14,15]$ and polymerase chain reaction (PCR) for molecular analysis of monogenic disorders [14,15] (Table 1). However, new methods of diagnosis requiring a whole-genome amplification (WGA) step to amplify a single cell DNA content prior to genetic analysis have been recently included in PGD/PGS clinical practice [16]. These techniques are array-comparative genomic hybridization (array-CGH) and single nucleotide polymorphism arrays (SNP-arrays) 
Table 1. Main methods of genetic diagnosis.

\begin{tabular}{ccc}
\hline & INDICATIONS & LIMITATIONS \\
\hline \multirow{3}{*}{ PCR } & Monogenic disorders & Contamination (high risk) \\
& Sexing & Allele drop-out \\
& & Preferential amplification \\
& & Amplification failure \\
& & Contamination (low risk) \\
FISH & Chromosome abnormalities & Mosaicism \\
& Sexing & Overlapping signals \\
& Aneuploidy screening & Failure of probes binding \\
\hline
\end{tabular}

$[16,17]$.

In order to obtain genetic material on which carry out genetic diagnosis, both PGD and PGS require the procedure known as biopsy which consists in the removal of one or more cells from the embryo/oocyte to be diagnosed. Biopsy is performed using a micromanipulator equipment. Since this is an invasive procedure, the choice concerning the appropriate timing and methodology requires particular attention in order to ensure an uncompromised and correct development of the biopsied oocyte/embryo and to allow an accurate diagnosis.

\section{BIOPSY}

Biopsy can be performed at three different stages: on oocytes or zygotes (polar body biopsy), on 6 - 10 cells embryos (cleavage stage biopsy) or on blastocysts (blastocyst biopsy), (Table 2). Independently from the procedure chosen, a biopsy involves two steps: 1) zona pellucida (ZP) drilling, which can be performed mechanically, chemically or by laser energy [18-20], and 2) cell/s removal.

\subsection{Polar Body Biopsy}

Polar body biopsy consists in the removal of the first polar body (PB) from an oocyte in order to diagnose the genetic status before insemination. This procedure is referred as to Pre-Conception Genetic Diagnosis (PCGD) [21]. The first PB is extruded during Meiosis-I and it is not required to achieve a correct fertilization and/or embryo development, so its removal has not any detrimental effect on oocyte competence. First PB biopsy allows the evaluation of the genetic maternal contribution by the identification of chromosomal abnormalities [22-24] or gene mutations $[15,25]$. Additionally, it has been recently applied for HLA typing [26] and for the diagnosis of $\mathrm{X}$-linked disorders [27].

The first use of PCGD was reported by Verlinsky and collaborators for cystic fibrosis screening on the first PB [28]. However, problems of misdiagnosis due to crossing-over events that can occur following fertilization, have shown that the second $\mathrm{PB}$, which is extruded during fertilization, is often required for an accurate diagnosis [24].
Table 2. Comparison between oocyte, embryo and blastocyst biopsy.

\begin{tabular}{|c|c|c|c|}
\hline & Oocyte & Embryo & Blastocyst \\
\hline $\begin{array}{l}\text { Aneuploidy from first meiotic } \\
\text { division }\end{array}$ & $\sqrt{ }$ & $\sqrt{ }$ & $\sqrt{ }$ \\
\hline $\begin{array}{l}\text { Aneuploidy from second } \\
\text { meiotic division }\end{array}$ & & $\sqrt{ }$ & $\sqrt{ }$ \\
\hline Female translocations & $\sqrt{ }$ & $\sqrt{ }$ & $\sqrt{ }$ \\
\hline Male translocations & & $\sqrt{ }$ & $\sqrt{ }$ \\
\hline Cleavage mistakes & & $\sqrt{ }$ & $\sqrt{ }$ \\
\hline Paternal contribution analyzed & & $\sqrt{ }$ & $\sqrt{ }$ \\
\hline $\begin{array}{c}\text { Recessive carrier's } \\
\text { identification }\end{array}$ & & $\sqrt{ }$ & $\sqrt{ }$ \\
\hline $\begin{array}{l}\text { Absence of influence on } \\
\text { embryo development }\end{array}$ & $\sqrt{ }$ & & $\sqrt{ }$ \\
\hline High DNA quantity & & & $\sqrt{ }$ \\
\hline Less biopsies to be performed & & & $\sqrt{ }$ \\
\hline Mosaicism effect reduced & & & $\sqrt{ }$ \\
\hline $\begin{array}{c}\text { Embryo selection and Single } \\
\text { Embryo Transfer }\end{array}$ & & & $\sqrt{ }$ \\
\hline Absence of ethical problems & $\sqrt{ }$ & & \\
\hline
\end{tabular}

Polar body biopsy is performed by aspiration for both first and second polar bodies. A hole in the ZP allows to access the perivitelline space, then a small beveled micropipette is used to gently aspirate the PB [29] (Figure 1). The timing of the procedure can differ according to indications. When only the first PB is required, aspiration is performed soon after oocyte retrieval, in order to avoid oocyte aging. When the second PB is required, aspiration can be performed simultaneously or sequentially. The sequential aspiration is performed by a two-step micromanipulation procedure: the first PB is removed soon after oocyte retrieval and the second after $6-14$ hours post fertilization [30]. On the contrary, the simultaneous removal of first and second PBs can be performed in a less invasive single-step micromanipulation procedure, 6 - 14 hours post fertilization [29].

Important aspects to consider

Polar body biopsy is a valid alternative to embryo biopsy for those couples who have ethical objections to embryo biopsy or in Countries with legal restrictions on PGD, such as Germany and Italy. However, PCGD allows only to analyze the maternal contribution and therefore cannot be performed in case of disorders of male origin or for sexing [15]. Furthermore, the need of biopsing both first and second PBs, in some cases may represent a limit for this technique. In fact, PBs have a different morphology: the first one usually has a crinkly appearance while the second is smooth, but the distinction between them can be difficult. For this reason sequential aspiration is often preferred to the simultaneous 
one.

\subsection{Cleavage Stage Biopsy}

Embryonic blastomeres are totipotent and this property ensures that the removal of few cells ( 1 or 2 ) does not affect the ability of the remaining cells to differentiate in all the cell lineages required for a correct development. Hardy and colleagues were the first authors to report that blastomere removal does not affect further embryo competence [31].

This procedure is usually performed on day- 3 post insemination, when embryos are at the $6-10$ cells stage. If performed at earlier stages ( 4 cells), the ratio of inner cell mass (ICM) to trophectoderm cells (TE) may be altered, while, if performed at the stage of compaction, cell removal can be very difficult and may result in cell lysis since strong contacts among adjacent blastomeres have been established. The use of $\mathrm{Ca}^{2+} / \mathrm{Mg}^{2+}$ free media during embryo biopsy can be helpful to overcome this problem. When incubated in such media, membrane adhesions between blastome- res are loosen, lowering the risk of cell lysis during cell removal and shortening the duration of the whole procedure [32].

Different methods for blastomere removal have been developed and all of them require a hole in the zona in order to access the perivitelline space. The most widely used procedure is blastomere aspiration: a small beveled aspiration pipette is introduced into the perivitelline space and one or two blastomeres are gently aspirated (Figure 2). An alternative method is the extrusion technique which can be performed by the "stitch and pull" [33] or by "flow" displacement [34].

\section{Important aspects to consider}

A main advantage of cleavage stage biopsy is that once the embryo biopsy has been performed embryo cryopreservation is not necessary, avoiding the risk of embryo damage or death following the freezing/thawing process [35].

Biopsy on day three gives a sufficient time lapse period for cell genetic diagnosis since embryo transfers can be performed at blastocyst stage, after 2 or 3 days from

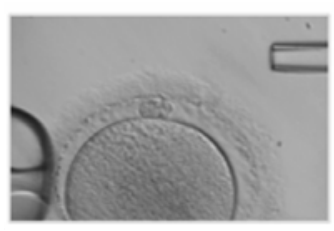

(a)

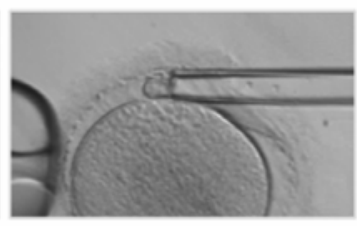

(b)

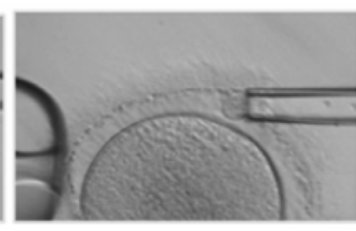

(c)

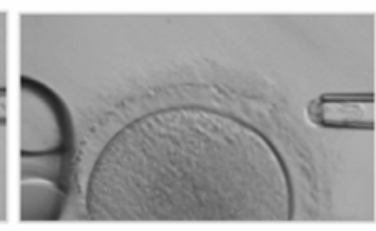

(d)

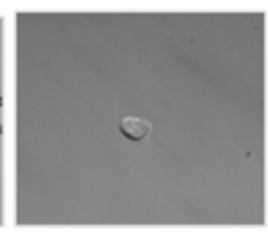

(e)

Figure 1. Polar body biopsy. Oocyte is held with a holding pipette and the polar body is extracted with a biopsy pipette ((a)-(d)). In picture (e) is visible the polar body removed from the oocyte.

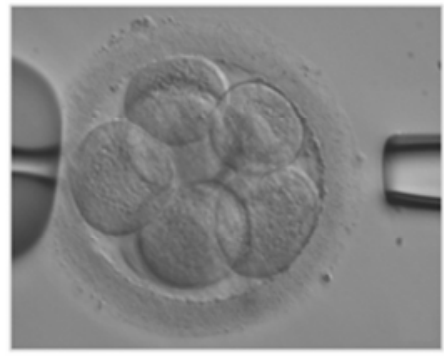

(a)

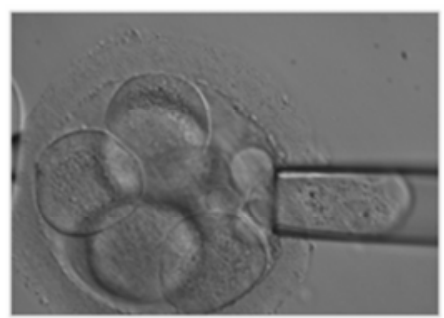

(e)

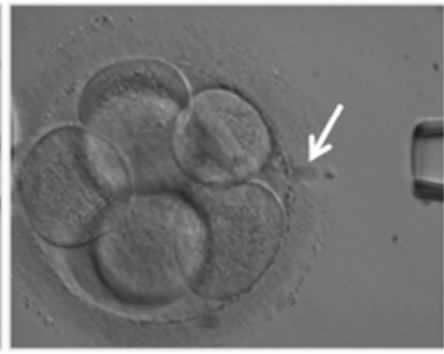

(b)

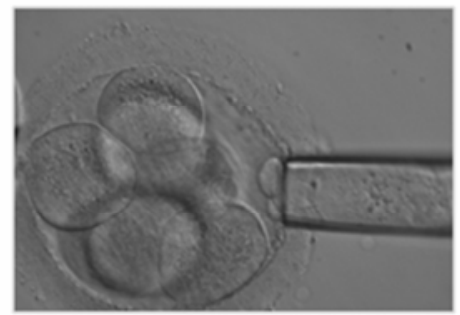

(f)

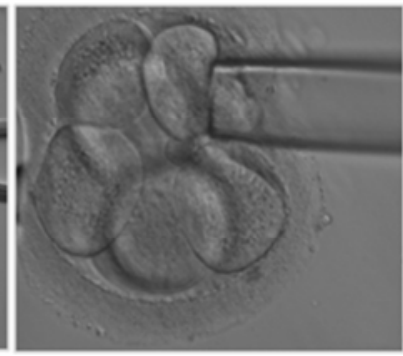

(c)

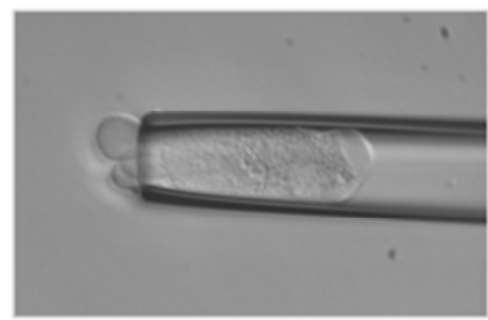

(g)

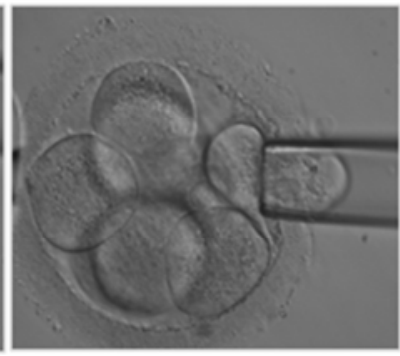

(d)

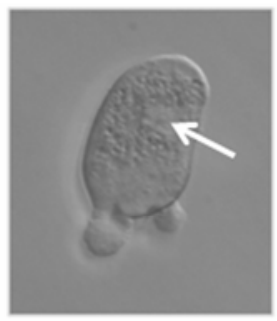

(h)

Figure 2. Embryo biopsy. The embryo is held with a holding pipette and one blastomere is removed with a biopsy pipette ((a)-(g)). In picture (b) the hole in the zona pellucida performed with laser is visible (arrow). The blastomere immediatly after the biopsy (h) with the nucleus clearly visible (arrow). 
the day of biopsy. Anyway, recent data have shown that embryo vitrification provides higher survival rates than conventional slow freezing [36].

One of the main issues concerning cleavage stage biopsy is the number of cells to aspirate. The choice of cell number for PGD should be the result of a balance between two aspects: an accurate and correct diagnosis of the embryo and the safeguard of its implantation potential. Two-cell analysis certainly provides a more reliable result, especially considering the problem of mosaicism. Chromosomal mosaicism is when different cells with a different chromosomal makeup coexist within the same individual who has developed from a single fertilized egg. In the past, high levels of mosaicism have been reported in cleavage stage embryos [37] and for this reason the analysis of two blastomeres or even more cells with the blastocyst stage biopsy (see the following paragraph) have been introduced. Anyway, data in the literature have shown that embryos with low-moderate chromosome mosaicism on day-3 often self-correct during their development to the blastocyst stage [38-40].

Recent studies have highlighted that the removal of 2 cells from a 8-cell embryo can result in an impaired implantation potential $[41,42]$. Therefore, the ESHRE PGD consortium recommends the biopsy of just one cell in PGS cycles: the aim of PGS is to improve embryo implantation and the removal of more than one cell would be more harmful than beneficial for the embryo [43]. However, the possibility of mosaicism should be taken into account.

Finally, in order to choose the blastomere to aspirate, the presence of a clearly visible nucleus should be considered since multinuceation or anucleation are frequently observed in cleavage stage embryos [44,45]. However, additional aspects such as the size, orientation, shape and volume of the blastomere, can significantly influence the outcome of the biopsy.

\subsection{Blastocyst Biopsy}

Blastocyst biopsy consists in the removal of the outer TE cells from a blastocyst without affecting the ICM, from which the fetus will develop. The introduction of improved culture media and sequential cultures have been the main factors leading to the current use of blastocyst biopsy in clinical practice since blastocyst formation is more easily achieved.

Blastocyst biopsy can be performed on day 5 or 6 . The removal of TE cells can be performed either by aspiration (Figure 3) or by the stitch and pull method. However, a third method called "herniation" can be used. In this case, a hole is drilled in the ZP, usually on day-3, and embryos are left in culture until day-5, when herniation of some of the TE cells should have occurred [46]. However, ICM cells may herniate instead of TE cells and for this reason some operators prefer to perform the hole in the zona on day-5 at the pole opposite to the ICM and wait few hours to ensure the herniation of TE cells [47].

\section{Important aspects to consider}

At the blastocyst stage, a larger number of cells can be removed from the embryo with respect to cleavage stage biopsy, allowing the retrieval of a higher amount of DNA and, thus, a more accurate diagnosis. However, a blastocyst biopsied on day- 5 cannot be kept in culture for more than $24 \mathrm{~h}$, therefore a shorter time is available for cell diagnosis and not all genetic laboratories are equipped to perform embryo diagnosis in such condition.

When the genetic results cannot be obtained within 24h from the biopsy cryopreservation should be considered as an alternative. Fortunately, different data in the literature report that blastocyst vitrification on day-5 or 6 is a successful method for cryopreservation with surprising higher survival rates than cleavage embryos in PGD programs $[48,49]$.

Usually, two to nine cells are removed from the trophectoderm without further compromising embryo development since ICM is not affected. The degree of chromosomal mosaicism detected at this stage is significantly lower compared to the one of embryos at the cleavage stage [50]. However, recent studies have indicated that mosaicism is a recurrent phenomenon also in blastocysts: TE cells may have diverged genetically from the ICM and they would not be representative of the rest of the embryo [51].

Despite the improvements obtained in culture media, blastocyst biopsy is not routinely carried out in PGD programs. Performing biopsy on day-5, the number of cycles suspended for the absence of embryos available for biopsy increases and it has been estimated that the number of cycles in which no embryo reaches the blastocyst stage are about $20 \%$ [46]. However the following consideration in support of blastocyst culture and biopsy should be taken into account: 1) a low number of embryos to process is more time and cost effective, and 2) most of the embryos that do not reach the blastocyst stage are chromosomally abnormal [52,53]. Blastocyst biopsy seems to be a better strategy as compared to cleavage stage biopsy also because different authors have reported that embryos diagnosed as aneuploid on day-3, later on day-5 have resulted in euploid blastocyst [38-40], suggesting the existence of self-correction mechanisms during the transition to blastocyst.

Finally, blastocyst biopsy can be considered as a valid alternative to embryo cleavage biopsy in FISH PGS cycles since ESHRE PGD consortium does not recommend embryo biopsy on day three for these couples [54].

\section{CONCLUSION}

PGD technology offers to couples at risk of transmitting a genetic disorder the chance to conceive a un-af- 


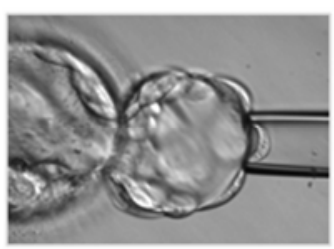

(a)

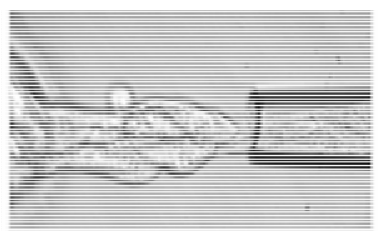

(f)

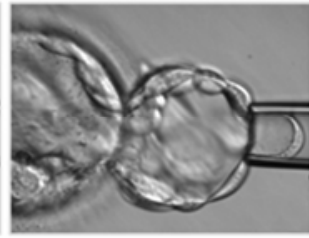

(b)

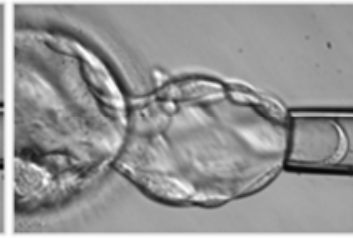

(c)

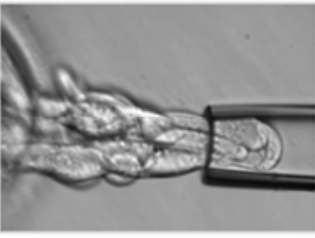

(d)

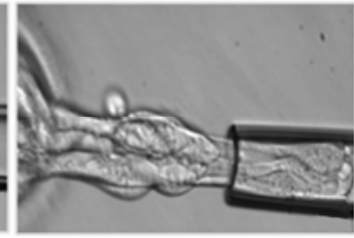

(e)

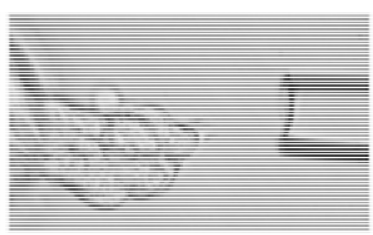

(g)

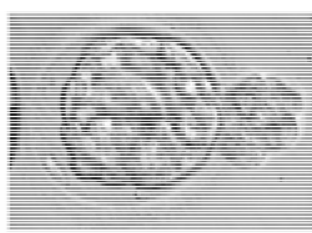

(h)

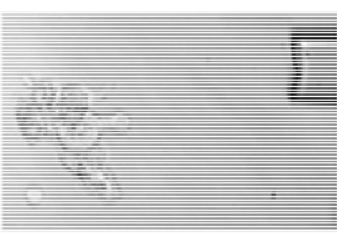

(i)

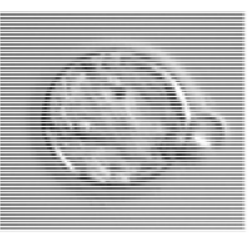

(j)

Figure 3. Blastocyst biopsy. Blastocyst is held with a holding pipette and few cells from the trophoectoderm are removed with a biopsy pipette ((a)-(g)). The blastocele collapses during the biopsy (h) and few hours of incubation are needed for the blastocyst to re-expand (j). In (i), the cells removed from the blastocyst are shown.

fected child by the diagnosis of the genetic status of embryos and subsequent transfer of those ones free from diseases. This procedure requires an invasive manipulation named biopsy which has to be performed by welltrained embryologists since both the choice of the methodology and the way it is carried out are of crucial importance for the final outcome of the PGD/PGS program. Only when the benefit of genetic analysis overcomes the negative aspects of the biopsy, the PGS/PGD procedure can be considered worthwhile.

\section{ACKNOWLEDGEMENTS}

The authors thank Dr Valentina Casciani, Ph.D., for her precious help in preparing and reviewing the manuscript.

\section{REFERENCES}

[1] Harper, J.C. and Sengupta, S.B. (2012) Preimplantation genetic diagnosis: State of the art 2011. Human Genetics, 131, 175-186. doi:10.1007/s00439-011-1056-Z

[2] Basille, C., Frydman, R., El Aly, A., Hesters, L., Fanchin, R., Tachdjian, G., Steffann, J., LeLorc'h, M. and AchourFrydman, N. (2009) Preimplantation genetic diagnosis: state of the art. The European Journal of Obstetrics \& Gynecology and Reproductive Biology, 145, 9-13. doi:10.1016/j.ejogrb.2009.04.004

[3] Whittaker, A.M. (2011) Reproduction opportunists in the new global sex trade: PGD and non-medical sex selection. Reproductive BioMedicine Online, 23, 609-617. doi:10.1016/j.rbmo.2011.06.017

[4] ESHRE PGD Consortium Steering Committee. (2002) ESHRE Preimplantation Genetic Diagnosis Consortium: Data collection III (May 2001). Human Reproduction, 17, 233-246. doi:10.1093/humrep/17.1.233

[5] Noble, R., Bahadur, G., Iqbal, M. and Sanyal, A. (2008) Pandora's box: Ethics of PGD for inherited risk of late- onset disorders. Reproductive BioMedicine Online, 17, 55-60. doi:10.1016/S1472-6483(10)60332-X

[6] Asscher, E. and Koops, B.J. (2010) The right not to know and preimplantation genetic diagnosis for Huntington's disease. Journal of Medical Ethics, 36, 30-33. doi:10.1136/jme.2009.031047

[7] Bellavia, M., Von Der Weid, N., Peddes, C., Jacquemont, S., Liebaers, I., Hohlfeld, P., Wunder-Galié, D. and De Ziegler, D. (2010) Preimplantation genetic diagnosis (PGD) for HLA typing: Bases for setting up an open international collaboration when PGD is not available. Fertility and Sterility, 94, 1129-1131. doi:10.1016/j.fertnstert.2009.11.007

[8] Pennings, G. and De Wert, G. (2003) Evolving ethics in medically assisted reproduction. Human Reproduction Update, 9, 397-404. doi:10.1093/humupd/dmg031

[9] Ly, K.D., Agarwal, A. and Nagy, Z.P. (2011) Preimplantation genetic screening: Does it help or hinder IVF treatment and what is the role of the embryo? Journal of Assisted Reproduction and Genetics, 28, 833-849. doi:10.1007/s10815-011-9608-7

[10] Mastenbroek, S., Twisk, M., Van der Veen, F. and Repping, S. (2011) Preimplantation genetic screening: A systematic review and meta-analysis of RCTs. Human Reproduction Update, 17, 454-466. doi:10.1093/humupd/dmr003

[11] Debrock, S., Melotte, C., Spiessens, C., Peeraer, K., Vanneste, E., Meeuwis, L., Meuleman, C., Frijns, J.P., Vermeesch, J.R. and D'Hooghe, T.M. (2010) Preimplantation genetic screening for aneuploidy of embryos after in vitro fertilization in women aged at least 35 years: A prospective randomized trial. Fertility and Sterility, 93, 364-373. doi:10.1016/i.fertnstert.2008.10.072

[12] Hardarson, T., Hanson, C., Lundin, K., Hillensjö, T., Nilsson, L., Stevic, J., Reismer, E., Borg, K., Wikland, M. and Bergh, C. (2008) Preimplantation genetic screening in women of advanced maternal age caused a decrease in clinical pregnancy rate: A randomized controlled trial. Human Reproduction, 23, 2806-2812. doi:10.1093/humrep/den217 
[13] Staessen, C., Platteau, P., Van Assche, E., Michiels, A., Tournaye, H., Camus, M., Devroey, P., Liebaers, I. and Van Steirteghem, A. (2004) Comparison of blastocyst transfer with or without preimplantation genetic diagnosis for aneuploidy screening in couples with advanced maternal age: A prospective randomized controlled trial. Human Reproduction, 19, 2849-2858. doi:10.1093/humrep/deh536

[14] Harper, J.C. (2009) Introduction to preimplantation genetic diagnosis. In: Harper, J.C., Ed., Preimplantation Genetic Diagnosis, Cambridge University Press, Cambridge, 1-47. doi:10.1017/CBO9780511581571.002

[15] Sermon, K. (2002) Current concepts in preimplantation genetic diagnosis (PGD): A molecular biologist's view. Human Reproduction Update, 8, 11-20. doi:10.1093/humupd/8.1.11

[16] Sermon, K. (2009) Preimplantation genetic diagnosis for monogenic disorders: Multiple PCR. In: Harper, J.C., Ed., Preimplantation Genetic Diagnosis, Cambridge University Press, Cambridge, 237-246. doi:10.1017/CBO9780511581571.016

[17] Munnè, S. (2009) Preimplantation genetic diagnosis for infertility (preimplantetion genetic screening). In: Harper, J.C., Ed., Preimplantation Genetic Diagnosis, Cambridge University Press, Cambridge, 203-229.

[18] Joris, H., De Vos, A., Janssens, R., Devroey, P., Liebaers, I. and Van Steirteghem, A. (2003) Comparison of the results of human embryo biopsy and outcome of PGD after zona drilling using acid Tyrode medium or a laser. $\mathrm{Hu}$ man Reproduction, 18, 1896-1902. doi:10.1093/humrep/deg355

[19] Chatzimeletiou, K., Morrison, E.E., Panagiotidis, Y., Prapas, N., Prapas, Y., Rutherford, A.J., Grudzinskas, G. and Handyside, A.H. (2005) Comparison of effects of zona drilling by non-contact infrared laser or acid Tyrode's on the development of human biopsied embryos as revealed by blastomere viability, cytoskeletal analysis and molecular cytogenetics. Reproductive BioMedicine Online, 11, 697-710. doi:10.1016/S1472-6483(10)61688-4

[20] Jones, A.E., Wright, G., Kort, H.I., Straub, R.J. and Nagy, Z.P. (2006) Comparison of laser-assisted hatching and acidified Tyrode's hatching by evaluation of blastocyst development rates in sibling embryos: A prospective randomized trial. Fertility and Sterility, 85, 487-491. doi:10.1016/j.fertnstert.2005.07.1314

[21] Verlinsky, Y., Ginsberg, N., Lifchez, A., Valle, J., Moise, J. and Strom, C.M. (1990) Analysis of the first polar body: Preconception genetic diagnosis. Human Reproduction, 5, 826-829.

[22] Munné, S., Dailey, T., Sultan, K.M., Grifo, J. and Cohen, J. (1995) The use of first polar bodies for preimplantation diagnosis of aneuploidy. Human Reproduction, 10, 10141020.

[23] Verlinsky, Y. and Kuliev, A. (1996) Preimplantation diagnosis of common aneuploidies in infertile couples of advanced maternal age. Human Reproduction, 11, 20762077. doi:10.1093/oxfordjournals.humrep.a019050

[24] Verlinsky, Y., Cieslak, J., Ivakhnenko, V., Evsikov, S., Wolf, G., White, M., Lifchez, A., Kaplan, B., Moise, J.,
Valle, J., Ginsberg, N., Strom, C. and Kuliev, A. (1998) Preimplantation diagnosis of common aneuploidies by the first- and second-polar body FISH analysis. Journal of Assisted Reproduction and Genetics, 15, 285-289. doi:10.1023/A:1022592427128

[25] Verlinsky, Y., Rechitsky, S., Cieslak, J., Ivakhnenko, V., Wolf, G., Lifchez, A., Kaplan, B., Moise, J., Walle, J., White, M., Ginsberg, N., Strom, C. and Kuliev, A. (1997) Preimplantation diagnosis of single gene disorders by two-step oocyte genetic analysis using first and second polar body. Biochemistry and Molecular Medicine, 62, 182-187. doi:10.1006/bmme.1997.2635

[26] Verlinsky, Y., Rechitsky, S., Schoolcraft, W., Strom, C. and Kuliev, A. (2001) Preimplantation diagnosis for Fanconi anemia combined with HLA matching. JAMA, 285 , 3130-3133.

[27] Verlinsky, Y., Rechitsky, S., Verlinsky, O., Kenigsberg, D., Moshella, J., Ivakhnenko, V., Masciangelo, C., Strom, C. and Kuliev, A. (2002) Polar body-based preimplantation diagnosis for X-linked disorders. Reproductive BioMedicine Online, 4, 38-42. doi:10.1016/S1472-6483(10)61913-X

[28] Verlinsky, Y., Rechitsky, S., Evsikov, S., White, M., Cieslak, J., Lifchez, A., Valle, J., Moise, J. and Strom, C.M. (1992) Preconception and preimplantation diagnosis for cystic fibrosis. Prenatal Diagnosis, 12, 103-110. doi:10.1002/pd.1970120205

[29] Montag, M., Van der Ven, K. and Van der Ven, H. (2009) Polar body biopsy. In: Harper, J.C., Ed., Preimplantation Genetic Diagnosis, Cambridge University Press, Cambridge, 166-174. doi:10.1017/CBO9780511581571.010

[30] Strom, C.M., Ginsberg, N., Rechitsky, S., Cieslak, J., Ivakhenko, V., Wolf, G., Lifchez, A., Moise, J., Valle, J., Kaplan, B., White, M., Barton, J., Kuliev, A. and Verlinsky, Y. (1998) Three births after preimplantation genetic diagnosis for cystic fibrosis with sequential first and second polar body analysis. American Journal of Obstetrics \& Gynecology, 178, 1298-1306. doi:10.1016/S0002-9378(98)70336-9

[31] Hardy, K., Martin, K.L., Leese, H.J., Winston, R.M. and Handyside, A.H. (1990) Human preimplantation development in vitro is not adversely affected by biopsy at the 8-cell stage. Human Reproduction, 5, 708-714.

[32] Dumoulin, J.C., Bras, M., Coonen, E., Dreesen, J., Geraedts, J.P. and Evers, J.L. (1998) Effect of $\mathrm{Ca}^{2+} / \mathrm{Mg}^{2+}$-free medium on the biopsy procedure for preimplantation genetic diagnosis and further development of human embryos. Human Reproduction, 13, 2880-2883. doi:10.1093/humrep/13.10.2880

[33] Muggleton-Harris, A.L., Glazier, A.M., Pickering, S. and Wall, M. (1995) Genetic diagnosis using polymerase chain reaction and fluorescent in-situ hybridization analysis of biopsied cells from both the cleavage and blastocyst stages of individual cultured human preimplantation embryos. Human Reproduction, 10, 183-92. doi:10.1093/humrep/10.1.183

[34] Roudebush, W.E., Kim, J.G., Minhas, B.S. and Dodson, M.G. (1990) Survival and cell acquisition rates after preimplantation embryo biopsy: Use of two mechanical tech- 
niques and two mouse strains. American Journal of $\mathrm{Ob}$ stetrics \& Gynecology, 162, 1084-1090.

doi:10.1016/0002-9378(90)91321-3

[35] Magli, M.C., Gianaroli, L., Fortini, D., Ferraretti, A.P. and Munné, S. (1999) Impact of blastomere biopsy and cryopreservation techniques on human embryo viability. Human Reproduction, 14, 770-773. doi:10.1093/humrep/14.3.770

[36] Keskintepe, L., Sher, G., Machnicka, A., Tortoriello, D., Bayrak, A., Fisch, J. and Agca, Y. (2009) Vitrification of human embryos subjected to blastomere biopsy for preimplantation genetic screening produces higher survival and pregnancy rates than slow freezing. Journal of Assisted Reproduction and Genetics, 26, 629-635. doi:10.1007/s10815-009-9369-8

[37] Harper, J.C., Coonen, E., Handyside, A.H., Winston, R.M., Hopman, A.H. and Delhanty, J.D. (1995) Mosaicism of autosomes and sex chromosomes in morphologically normal, monospermic preimplantation human embryos. Prenatal Diagnosis, 15, 41-49.

doi:10.1002/pd.1970150109

[38] Li, M., DeUgarte, C.M., Surrey, M., Danzer, H., DeCherney, A. and Hill, D.L. (2005) Fluorescence in situ hybridization reanalysis of day-6 human blastocysts diagnosed with aneuploidy on day 3 . Fertility and Sterility, 84, 1395-1400. doi:10.1016/j.fertnstert.2005.04.068

[39] Barbash-Hazan, S., Frumkin, T., Malcov, M., Yaron, Y., Cohen, T., Azem, F., Amit, A. and Ben-Yosef, D. (2009) Preimplantation aneuploid embryos undergo self-correction in correlation with their developmental potential. Fertility and Sterility, 92, 890-896. doi:10.1016/j.fertnstert.2008.07.1761

[40] Munné, S., Velilla, E., Colls, P., Garcia Bermudez, M., Vemuri, M.C., Steuerwald, N., Garrisi, J. and Cohen, J. (2005) Self-correction of chromosomally abnormal embryos in culture and implications for stem cell production. Fertility and Sterility, 84, 1328-1334. doi:10.1016/j.fertnstert.2005.06.025

[41] Cohen, J., Wells, D. and Munné, S. (2007) Removal of 2 cells from cleavage stage embryos is likely to reduce the efficacy of chromosomal tests that are used to enhance implantation rates. Fertility and Sterility, 87, 496-503. doi:10.1016/j.fertnstert.2006.07.1516

[42] Goossens, V., De Rycke, M., De Vos, A., Staessen, C., Michiels, A., Verpoest, W., Van Steirteghem, A., Bertrand, C., Liebaers, I., Devroey, P. and Sermon, K. (2008) Diagnostic efficiency, embryonic development and clinical outcome after the biopsy of one or two blastomeres for preimplantation genetic diagnosis. Human Reproduction, 23, 481-492. doi:10.1093/humrep/dem327

[43] Harton, G.L., De Rycke, M., Fiorentino, F., Moutou, C., SenGupta, S., Traeger-Synodinos, J. and Harper, J.C. (2011) ESHRE PGD consortium best practice guidelines for amplification-based PGD. Human Reproduction, 26, 33-40. doi:10.1093/humrep/deq231

[44] Van Royen, E., Mangelschots, K., Vercruyssen, M., De Neubourg, D., Valkenburg, M., Ryckaert, G. and Gerris, J. (2003) Multinucleation in cleavage stage embryos. Hu- man Reproduction, 18, 1062-1069. doi:10.1093/humrep/deg201

[45] Hardy, K., Winston, R.M. and Handyside, A.H. (1993) Binucleate blastomeres in preimplantation human embryos in vitro: Failure of cytokinesis during early cleavage. Journal of Reproduction and Fertility, 98, 549-558. doi:10.1530/jrf.0.0980549

[46] McArthur, S.J., Leigh, D., Marshall, J.T., de Boer, K.A. and Jansen, R.P. (2005) Pregnancies and live births after trophectoderm biopsy and preimplantation genetic testing of human blastocysts. Fertility and Sterility, 84, 16281636. doi:10.1016/j.fertnstert.2005.05.063

[47] Kokkali, G., Vrettou, C., Traeger-Synodinos, J., Jones, G.M., Cram, D.S., Stavrou, D., Trounson, A.O., Kanavakis, E. and Pantos, K. (2005) Birth of a healthy infant following trophectoderm biopsy from blastocysts for PGD of beta-thalassaemia major. Human Reproduction, 20, 1855-1859. doi:10.1093/humrep/deh893

[48] Vajta, G. and Kuwayama, M. (2006) Improving cryopreservation systems. Theriogenology, 65, 236-244. doi:10.1016/j.theriogenology.2005.09.026

[49] Escribá, M.J., Zulategui, J.F., Galán, A., Mercader, A., Remohí, J. and de los Santos, M.J. (2008) Vitrification of preimplantation genetically diagnosed human blastocysts and its contribution to the cumulative ongoing pregnancy rate per cycle by using a closed device. Fertility and Sterility, 89, 840-846. doi:10.1016/j.fertnstert.2007.04.035

[50] Evsikov, S. and Verlinsky, Y. (1998) Mosaicism in the inner cell mass of human blastocysts. Human Reproduction, 13, 3151-3155. doi:10.1093/humrep/13.11.3151

[51] Fragouli, E., Alfarawati, S., Daphnis, D.D., Goodall N.N., Mania A., Griffiths T., Gordon A. and Wells D. (2011) Cytogenetic analysis of human blastocysts with the use of FISH, CGH and a CGH: Scientific data and technical evaluation. Human Reproduction, 26, 480-490. doi:10.1093/humrep/deq344

[52] Sandalinas, M., Sadowy, S., Alikani, M., Calderon, G., Cohen, J. and Munné, S. (2001) Developmental ability of chromosomally abnormal human embryos to develop to the blastocyst stage. Human Reproduction, 16, 1954-1958. doi:10.1093/humrep/16.9.1954

[53] Clouston, H.J., Herbert, M., Fenwick, J., Murdoch, A.P. and Wolstenholme, J. (2002) Cytogenetic analysis of human blastocysts. Prenatal Diagnosis, 22, 1143-1152. doi: $10.1002 / \mathrm{pd} .502$

[54] Harton, G.L., Harper, J.C., Coonen, E., Pehlivan, T., Vesela, K. and Wilton, L. (2011) ESHRE PGD consortium best practice guidelines for fluorescence in situ hybridization-based PGD. Human Reproduction, 26, 25-32. doi:10.1093/humrep/deq230 


\section{ABBREVIATIONS}

AMA

CGH

FISH

ICM

PCGD
Advanced maternal age

Comparative genomic hybridization Fluorescent in situ hybridization Inner cell mass

Pre-conception genetic diagnosis
PCR

PGD

PB

PGS

TE

WGA
Polymerase chain reaction

Preimplantation genetic diagnosis Polar body

Preimplantation genetic screening Trophectoderm cells

Whole-genome amplification 